\title{
Remembranza de la Escuela César Conto: transformaciones socioculturales, dolor y sufrimiento sobre el emblemático caso de Bojayá"
}

\author{
Carlos Enrique Mosquera* \\ Jhon Fredy Tique Bastos ${ }^{* * *}$
}

Recibido: 22 de julio de 2015 Evaluado: 18 de septiembre de 2015 Aceptado: 30 de septiembre de 2015

\section{Resumen}

Este artículo es producto de una investigación cuyo objetivo consistió en comprenderlos relatos de algunos actores escolares de la comunidad de la Institución Educativa Departamental César Conto, Bojayá, Chocó, como un elemento relevante para la recuperación de su memoria colectiva sobre la masacre del2 de mayo de 2002. Para este fin, se utilizó como metodología la hermenéutica, dado que facilitó el entendimiento de las voces de los actores seleccionados. La investigación develó: 1) el sentido y significado de la masacre paralas personas objeto de estudio; 2) las afectaciones para el proceso educativo; 3) las transformaciones socioculturales para la escuela, el pueblo de Bojayá y sus alrededores; 4) las violaciones de los derechos humanos y derecho internacional humanitario; y 5) las responsabilidades del Estado, los actores armados, empresarios y latifundistas en el conflicto armado que se ha librado en esta parte del país.

Palabras claves: conflicto armado,escuela, escuela y memoria colectiva, masacre.

\footnotetext{
* Artículo de investigación. Es el resultado final de un proyecto de investigación adelantado en la Maestría en Educación en la Universidad Santo Tomás, Bogotá, el cual recibío calificación de Meritoria Honorífica. Cómo citar este artículo: Mosquera, C.E., y Tique Bastos, J.F. (2016). Remembranza de la Escuela César Conto: transformaciones socioculturales, dolor y sufrimiento sobre el emblemático caso de Bojayá. Hallazgos, 13(25), 177-197 (doi: http://dx.doi.org/10.15332/s1794-3841.2016.0025.08).

** Licenciado en Filosofía y Educación Reliogiosade la Universidad Católica de Oriente (Colombia);magíster en Educación de la Universidad santo Tomás (Colombia) y estudiante de Doctorado en Educación de la Universidad Nacional de Rosario (Argentina). Docente investigador, labora en la Secretaría Departamental de Antioquia de tiempo completo (Colombia). Correo electrónico: carlosfilosofo@hotmail.com

*** Licenciado en Lengua Castellana y Literatura, de la Universidad de la Amazonia (Colombia); especialización en Medio Ambiente, de la misma universidad; magíster en Educación de la Universidad santo Tomás yestudiante de Doctorado en Educaciónde la Universidad Nacional de Rosario (Argentina).Profesor investigador, labora en la Secretaría Departamental de Caquetá de tiempo completo (Colombia). Correo electrónico: jhonftb@ hotmail.com
} 


\section{Recovery of the collective memory about Bojaya-Choco's slaughter taking into account the actors' voices of the César Conto Departamental Educational Institution}

\begin{abstract}
This article represents the final result of a research project. The purpose was Understanding the stories of some voices of actors schoolchildren the collective memory of the César Conto Departamental Educational Institution about the slaughter from Bojayá, Chocó, as a relevant element to the recovery of collective memory. For this purpose, it was used as a methodology, because it made easy the understanding of the voices of the chosen actors. The research revealed: One) the sense and the meaning of the slaughter for the people; two) the affectations to the educative process; three) the sociocultural transformations and the impact lived for the César Conto Departamental school, Bajaya town and its surroundings; four) theViolations of Human Rights and International Humanitarian Law; and five) the responsibility of the Colombian Statebusinessmen and landowners in the armed conflict that has been waged in this part of the country
\end{abstract}

Key words: Armed conflict,collective memory, school, school and memory, slaughter.
Received: July 22, 2015

Evaluated: September 18, 2015

Accepted: September 30, 2015 


\section{Lembranças da Escola César Conto: transformações socioculturais, dor e sofrimento sobre o emblemático caso de Bojayá}

Recebido: 22 de julho de 2015

Avaliado: 18 de setembro de 2015

Aceito: 30 de setembro de 2015

\section{Resumo}

Este artigo é produto de uma pesquisa cujo objetivo consistiu em compreender relatos da Instituição Educativa Departamental César Conto, Bojayá, Chocó, como um elemento relevante para a recuperação da memória coletiva da comunidade sobre o massacre de 2 de maio de 2002. Portanto, utilizou-se a metodologia hermenêutica, visando facilitar o entendimento das vozes dos atores selecionados. A pesquisa abordou: 1) o sentido e significado do massacre para o grupo objeto de estudo; 2) os efeitos para o processo educativo; 3 ) as transformações socioculturais para a escola, a população de Bojayá e seu entorno; 4) as violações dos direitos humanos e do direito internacional humanitário e 5) as responsabilidades do Estado, dos atores armados, empresários e latifundiários no conflito nesta parte do país.

Palavras-chave: conflito armado, escola e memória coletiva, massacre. 


\section{INTRODUCCIÓN}

El conflicto armado interno que ha vivido Colombia por más de medio siglo supera en términos cuantitativos la escalofriante cifra de víctimas, según la Comisión Nacional de Reparación y Reconciliación (CNRC) (2013) en su informe “¡Basta ya! Colombia: memoria de guerra y dignidad: más de 220.000 personas muertas en el contexto nacional. Lo preocupante es que este conflicto armado ha llegado hasta las fronteras de la escuela; por tanto, parte de esas cifras pertenecen a los actores educativos. Es el caso concreto de la masacre de Bojayá en 2002, donde la comunidadeducativa de la Institución Educativa Departamental César Conto (en adelante, IE DCC) del municipio de Bojayá, Chocó, ubicada en la cabecera municipal de Bellavista, fue víctima de la confrontación armada entre las Autodefensas Unidas de Colombia (AUC) y las Fuerzas Armadas Revolucionarias de Colombia (FARC-EP). Confrontación que dejó un saldo aterrador de 119 personas muertas. Lo lamentable es que muchos de los actores eduativos pertenecíana esta instituiónescolar.

Este funesto hecho cambió la vida de estos actores educativos al experimentarlas pérdidas humanas, las materiales, las simbólicas, la pérdida del espacio escolar, la situación de vivir en la orfandad, al vivenciar la díaspora del desplazamiento, en fin, una serie de transformaciones socioculturales que modificaron su estilo de vida.

Por lo anterior, el alcance de la presente investigación se basó en recuperar la memoria colectiva sobre la masacre, mediante la comprensión de algunas voces deactores escolares, tomadola hermenéutica como metodología. En consecuencia, se da un esfuerzo emprendido desde la academia para entender lo que ha pasado en Bojayá, y para que masacres como la del 2 de Mayo de 2002 no sea vista como un dato o un suceso más que ha pasado a la historia doce años después; es decir,no debe verse sometida al olvido por parte del Estado ni de los imaginarios colectivos, teniendo en cuenta la magnitud de esta; también, para evitar la impunidad, garantizarle el derecho a las víctimas a restituirlas con dignidadypara reparar el dañoacusado.

De igual manera, porque el ejercicio de la recuperación de la memoria desde la escuela,además de visibilizar sus relatos como apuesta de construcción colectiva, permite dar cuenta de hechos y acontecimientos de gran envergadura desde otras miradas diferentes a la historia oficial, toda vez que el conflicto armado transformó la vida de los habitatantes de esta parte de la nación colombiana.

También, porque posibilita denunciar las violaciones de los derechos humanos y Derecho Internacional Humanitario (DIH) en esta zona, ya que los grupos armados(fuerzas militares, guerrilleros, paramilitaresobandas criminales) han cometidomuchosvejámnes en estos territorios chocoanos.

\section{Metodología}

La metodología seleccionadafue la hermenéutica, entendiéndola como la propone Merlino (2009) al afirmar que "La hermenéutica, esmetodológicamente, un mecanismo de comprensión de la intencionalidad del otro, intencionalidad que sólo puede entenderse en su contexto" (p. 54). También porque la hermenéutica facilita el entendimiento de textos orales y escritos. 
Tabla 1. Población objeto de estudio

\begin{tabular}{|c|c|c|c|}
\hline Número & Actores & Edad & Criterios \\
\hline 1 & $\begin{array}{l}\text { Estudiante } \\
\text { antiguo }\end{array}$ & 25 & $\begin{array}{l}\text { Sobreviviente que dé cuenta dela masacre, su incidencia de la masacre } \\
\text { en la escuela y en latransición del proceso educativo, teniendo en } \\
\text { cuenta su reubicación y su nueva apertura, lo que ha significado } \\
\text { la masacre de Bojayá y la pérdida de muchos de sus amigos, y que } \\
\text { pueda dar cuenta también de la suerte de los estudiantes y maestros } \\
\text { en su momento. }\end{array}$ \\
\hline 7 & $\begin{array}{l}\text { Estudiantes } \\
\text { vigentes } \\
\text { por grados } \\
10^{\circ} \text { y } 11^{o}\end{array}$ & $16-20$ & $\begin{array}{l}\text { Los sujetos focalizados son estudiantes vigentes de la generación } \\
\text { actual, que han perdido familiares, para saber qué sentido y signifi- } \\
\text { cado le dan al evento del } 2 \text { de mayo de } 2002 \text { y cómo hace memoriala } \\
\text { escuela sobre la masacre. }\end{array}$ \\
\hline 1 & Rector & 58 & $\begin{array}{l}\text { Saber sobre las experiencias de la comunidad educativa frente a los } \\
\text { hechos del crimen de Bojayá,lo que ha significado la masacre para } \\
\text { la comunidad educativa, al igual que la pérdida de estudiantes de la } \\
\text { época y cómo la institución hace memoria de estos hechos. }\end{array}$ \\
\hline 1 & $\begin{array}{l}\text { Docente } \\
\text { antiguo }\end{array}$ & 42 & $\begin{array}{l}\text { Docente antiguo que suministre información sobre la afectación } \\
\text { material, psicológica y pedagógica de la comunidad educativa en su } \\
\text { entonces; qué pasó conestudiantes y docentes a raíz de la masacre, } \\
\text { cómo fue la reubicaciónde la escuela y su nueva apertura, la transi- } \\
\text { ción del proceso educativo. }\end{array}$ \\
\hline 1 & $\begin{array}{l}\text { Madre } \\
\text { de } \\
\text { familia }\end{array}$ & 48 & $\begin{array}{l}\text { Sobreviviente, que además de hacer memoria de su experiencia, } \\
\text { proporcione información acerca de cómo ha impactado a la actual } \\
\text { generación de estudiantes: qué impacto ha tenido para la escuela ser } \\
\text { afectada en su estructura física, la pérdida de vidas humanas de vario- } \\
\text { sestudiantes, transición del proceso educativo y qué les ha significado } \\
\text { el traslado de la institución educativa, así como las transformaciones } \\
\text { socioculturales presentadas que se han dado debido a la masacre de } \\
\text { Bojayá. }\end{array}$ \\
\hline 1 & $\begin{array}{l}\text { Docente } \\
\text { nuevo }\end{array}$ & 33 & $\begin{array}{l}\text { Docente que no presenció los hechos que dé cuenta de las expe- } \\
\text { riencias de los estudiantes sobre estos hechos, cómo la institución } \\
\text { educativa (estudiantes, docentes, directivos y padres de familia) hace } \\
\text { memoria de la masacre y lo que piensa sobre las afectaciones psico- } \\
\text { lógicas de muchos estudiantes de la institución educativa que han } \\
\text { perdido familiares. }\end{array}$ \\
\hline
\end{tabular}

Fuente: Calos Enrique Mosquera yJhon Fredy Tique (2014).

Así pues, la población objeto de estudio fue seleccionada teniendo en cuentacriterios del equipo investigador:fueron 12 actores de la IEDCC, como se detalla a continuación (ver tabla 1).

Vale la pena repetir que dicha investigación se llevó a cabo en el contextode la IEDCCdeBellavista, cabecera municipal de Bojayá, Chocó. Los instrumentos utilizados fueron la entrevista a profundidad ${ }^{1}$, grupo focal y diario de campo.En este sentido, se aplicaron y codificaron las entrevistas de la siguiente manera: la entrevista 1, que se le hizo al rector, seidentificó como (J.M 2012).

1 Las entrevistas se pueden encontrar en el informe de investigación Recuperación de la memoria colectiva sobre la masacre de Bojaya -Chocó, a partir de algunas voces de actores de la Institución Educativa Departamental César Conto ( 2014) en las instalaciones de la Universidad Santo Tomás, de Bogotá. 
La entrevista 2, que fue hecha a un estudiante antiguo, que para esta fecha es profesional, se identificó como (M.M 2012). La entrevista 3 , realizada a un docente nuevo que no presenció la masacre, se identificó como (W.D 2012). La entrevista 4, quese hizo a un docente antiguo sobreviviente, y que actualmente es coordinador, se identificó como (G.U 2012). La entrevista 5, realizada a una madre de familia que para esa época era profesora, se identificó como (E.F 2012). Para el grupo focal se seleccionaron siete estudiantes, los cuales se identificaron como(M.V 2012), (R.V 2012), (J.P 2012), (E.L 2012), (V.M 2012), (M.N 2012), (W.C 2012), las impresiones del diario de campo, como (D.C 2012).

De igual modo, se tuvieron en cuenta fuentes suplementarias, como videos, registro fotográfico y revisiones documentales de hemerotecas y periódicos, para así tratar de conocer las diversas versiones sobre lo sucedido y entender mejor el problema de estudio; sin olvidar que el interés investigado era la memoria colectiva. El análisis se guió por dos categorías principales: conflicto armado y masacre en Bojayá, con lassu-categorías: escuela y conflicto armado; de ellas surgieron otras categorías emergentes.

\section{Resultados}

Para una mejor comprensión de los resultados, el equipo de investigadores optó por dividirlos en dos partes: hallazgos relacionados con el pueblo de Bojayá y sus alrededores, y hallazgos relacionados con la Institución Educativa Departamental César Conto, para responder atodos los objetivos del estudio.

\section{Hallazgos relacionados CON EL PUEBLO DE BOJAYÁ Y SUS ALREDEDORES}

El fenómenomás alarmante de la lucha armada colombiana es el que se revela en el uso planificado y repetido de la masacre como estrategia terrorista, por su carácter de homicidio colectivo, premeditado, sevicia, y por su tendencia exterminadora. El empleo de la masacre deja ver la degradación y la bajeza a la que ha llegado el conflicto armado. Lo más lamentable es que los actores que alimentan laguerra y dejan miles de víctimas argumentan que en toda guerra hay un precio humano que pagar: muertes selectivas, atentados, masacres, desaparición forzada, secuestros, desplazamientos, ataque a las escuelas. Todo esto es vistocomo algo natural e inevitable enlos conflictos armados. Pero tal afirmación es con la intención de ocultar la variedad de los verdaderos intereses que mueven la guerra.

En este contexto, el presente estudio quiere aportar en el desvelamiento de esos intereses que promueven la guera en esta zona, mediante el ejercicio de recuperación de la memoria de la masacre de Bojayá, como se detalla a continuación.

1. La presencia del conflicto armado en esta región del Pacífico colombiano, donde está ubicado Bojayá, está marcada por intereses económicos y estratégicos de diversos actores: gubernamentales, latifundistas, transnacionales, empresarios y actores armados; dadas las bondades y riquezas que posee la zona del medio y bajo Atrato, para el desarrollo de diferentes actividades y 
proyectos. Esto se corrobora en el siguiente relato al afirmar:

Pues oiga, le digo que para nosotros por ejemplo, ha sido un marcante, que eso lo lleva uno de por vida. La masacre, masacrar digamos a 119 personas es una cosa que fue bastante dolorosa y muy fuerte. Recuerdo esta zona era muy pacífica. Desafortunadamente digamos por los problemas sociales, económicos, posesión de tierra, pues en los últimos años a partir, digamos, del 80 por acá nos vimos afectados, digamos, por el flagelo de la violencia, donde comenzaron a penetrar grupos al margen de la ley, donde estuvo su mayor furor desde, desde los años 90 al 2000, 2002, donde el 2002 ,digamos, como dice uno, estalló, llegó al máximo nivel la violencia, que trajo como consecuencia un enfrentamiento entre los paramilitares y la guerrilla, donde la gente, digamos, la mayoría se alojó en la Iglesia. GU (2012)

Sin duda alguna, la presencia de grupos al margen de la ley en esta zona obedece a varios intereses económicos y de estrategia militar por las bondades económicas y estratégicas que representa esta regióndel occidente chocoano. Esto también es evidenteenBelloetal., (2005) sostienenque el conflicto en esta región se da por eleje de conexión de grandes proyectos de infraestructura y de interconexión energética vial entre las Américas: proyecto Iniciativa para la Integración de la Infraestructura Regional Suramericana (IIRSA), y el proyecto Plan Puebla Panamá, ahora conocido como Plan Mesoamérica.Elprimerofueplanificado para la conexión vial y energética de toda América, y el segundo fue propuesto para el mejoramiento de la infraestructura y la extracción de recursos de los países de Mesoamérica. Estos dos proyectos se interconectarían precisamente en la región del Atrato en la cual se encuentra Bojayá -mediante el canal interoceánico Atrato-Napipi-.

Sin duda, esto explica la presencia de los actores armados en esta zona, lo que permite inferir que la masacre del 2 de mayo de 2002, donde murieronalrededorde 119 personas que se refugiaban de los combates en la iglesia de la cabecera municipal de Bojayá, Chocó, entre miembros de las FARC-EP y lasAUC, no es un hecho fortuito, aislado de los intereses que aquí se develan; por el contrario, ante la situación descrita, la masacre se convierte en una especie de crónica de una muerte anunciada para esta región que desde hacía muchos años venía siendo objeto de hostilidad y desplazamiento, es decir, azotada por el conflicto armado.

La anterior situación también es denunciada por la Comisión Nacional de Reparación y Reconciliación (2010), cuando declarara:

La expansión del monocultivo de palma aceitera pudo ser apoyada por los paramilitares porque garantizaban un cambio en el poblamiento y en el paisaje del Bajo Atrato, acercándolo al modelo del paisaje de Urabá con el monocultivo de banano que debería permitirles arrebatar definitivamente el control del territorio a la guerrilla de las FARC, en un momento en el que el balance de fuerzas con ellas en el Atrato era incierto. La misma expansión del paramilitarismo tuvo intereses antisubversivos, pero también de apoyo a 
proyectos económicos, y ala consolidación de un proyecto político que se extendería a varias regiones, en procura de la articulación de las Autodefensas Campesinas de Córdoba y Urabá ACCU - y de otros grupos paramilitares como las Autodefensas Unidas de Colombia AUC, en un proyecto de unidad nacional. (p.167).

Esta problemática la ponen igualmente de manifiesto Belloetal., (2005), al considerar que "las disputas territoriales se asocian además con las dinámicas que generan en la región el aumento de los cultivos de uso ilícitos, la proliferación de monocultivos como la palma africana y la explotación maderera"'(p. 41).

No cabe duda entonces de que los intereses que produjeron la masacre tienen que ver con el despojo de las tierras de esta zona del país, dado que son aptas para muchas actividades: siembra diversa, en especial para la palma de aceite, ganadería extensiva, creación de hidroeléctricas dada su riqueza hidrográfica, exportación de maderera, rutas para el comercio de estupefacientes con Centro América, Panamá y los dos océanos Pacífico y Atlántico, así como de varios mega proyectos de infraestructura y de interconexión energética y vial entre las Américas.

2. El desplazamiento forzado obedece a una estrategia de actores amados, empresarios ylatifundistas, para apoderarse de las tierras de esta parte del país. Así se manifuestaenla siguiente voz:

Vivimos muy agradecidos con la Curia, con la Diócesis de Quibdó, que fueron los pioneros para que retornáramos, porque no nos convenía quedarnos en Quibdó, porque eso era darle tiempo al León para que se ocupara de nuestras tierras. Como todo el mundo sabe, para todo el mundo eso es claro... De que aquí quieren sacarnos del territorio, se quieren adueñarse del territorio, entonces a nosotros no nos convenía.E.F (2012)

Se recuerda que hay registros investigativos sobre el apoyo de la fuerza pública a los paramilitares para el dominio y control de esta zona. La alianza militar que han tenido las fuerzas militares con paramilitares es algo real; fue efectuada en su momento sin ningún impedimento,así lo revelan Bello etal., (2005) al describir la convivencia del Ejército con grupos paramilitares:

Fue durante la década de los 90 en la cual el proyecto paramilitar tomó más fuerza, la intención de "limpiar" la región de un enemigo común, significó la unificación de tareas militares conjunta por parte del Ejército, la Marina y las autodefensas, específicamente del Bloque Elmer Cárdenas de las AUC. Ejemplo claro de esto fue la Operación Génesis, iniciada en febrero de 1997 que generó el desplazamientoentre 15 mil y 17 mil afro descendientes. (p. 45)

El Informe defensoría humanitario (Defensoría del Pueblo (25 de mayo de 2002) explica que los paramilitares se movían en todo el Atrato, $\mathrm{y}$ pasabandesapercibidos por los retenes militares, porque:

En el trayecto de Turbo a Vigía del Fuerte, todas las embarcaciones que transitan por el río Atrato deben pasar por los retenes de la Armada Nacional, 
Batallón Fluvial 50, ubicados en el sitio conocido como La Punta, a la salida de Turbo, y en Riosucio. Al parecer, las embarcaciones antes mencionadas no fueron observadas o identificadas por los responsables de los retenes en la zona. (p.1)

El hecho de que las fuerzas armadas constituidas legalmente que están para proteger a los colombianos hagan alianzas con grupos al margen de la ley, constituye un asunto grave. El mismo informe de la Comisión Nacional de Reparación y Reconciliación (2010) revela que el Estado a través del Ejercito Nacional apoyó muchas de las acciones contra la población civil, y facilita así la logística y apoyo militar antes de la masacre. Pero también, después de la masacre, cuando afirma que muchos paramilitares heridos fueron sacados de Bojayá y vestidos como civiles por el Ejército Nacional, y las personas reconocían sus pertenencias, las cuales eran llevadas por los paramilitares.

Lo anterior tiene asiderotambiénen la voz de un estudiante sobreviviente cuando narra lo sucedido aldía siguiente del evento del 2 de mayo:

Como en ese tiempo nos desplazamos, muchos de los guerrilleros y paramilitares cogían la ropa de uno, cuando uno estaba en Vigía, uno decía, o le decía uno al compañero: aah, ¡mira ese es mi suéter! ¡Esa es su pantaloneta!; pues ni modo de decirle algo, para ganarse la muerte ahí por un suéter. M.V (2012)

Todo estodemuestra lo permisivo que ha sido el Estado desde hace mucho tiempo, al asentir por acción u omisión los desplazamientos y muertes que ha generado el conflicto armado a estas poblaciones, violando los derechos humanos y el derecho internacional humanitario. En consecuencia, el Centro de Investigación y Educación Popular (2002) ilustra cómo desde 1997 la Alta Comisionada de los Derechos Humanos de las Naciones Unidas presentó en un informe su preocupación por la convivencia entre miembros de la fuerza pública y los paramilitares, y así constituyó su accionar conjunto en una serie de violaciones a los derechos humanos de estos pobladores. El mismo Jefe de los paramilitares en esa zona, Freddy Rendón“El Aleman”, en sus versiones libres, ha contado al país la forma como varios de sus hombres guiaban a la Fuerza Aérea Colombina para acabar los campamentos de las FARC (Verdad Abierta, 2009).

En suma, la responsabilidad del Estado y la fuerza pública ha sido tan evidente que, por ejmplo, el Concejo de Estado en Sentencia del 17 de septimbre de 2015 deja en firme la desición de condenar al Estado y a la fuerza publica por omisión, por no proteger a los bellavsisteños del ataque de los grupos armados ilegales en contra de la población civil.

3. El conflicto armado ha generado en los habitantes de Bojayá y sus alrededores, transformaciones socioculturales que han incidido en la forma de subsistencia, medios de producción, bienestar económico y tranquilidad social, por las limitaciones que impone el conflicto para realizar sus labores diarias. Para los bellavisteños, alejarse de Bojayá representa peligro, y ya no pueden realizar libremente sus actividades productivas, como lo afirma a continuación este actor educativo: 
Acá, o sea a raíz de lo que paso allá, en el mismo pueblo viejo antes de venirnos acá, no se daba lo que estamos viviendo, esto fue algo muy duro que ya la gente dejo de, de acudir al monte porque la violencia siempre estaba. La violencia siempre ha estado aquí, o sea, que ya nosotros aquí, como que uno tiene que aprender como a vivir con el uno y con el otro, o con los dos; si no está la fiera, está el León. Si no está el Tigre está él, pero de que están aquí están. En ocasiones, digamos, las comunidades indígenas, en los caminos se encuentran las minas quiebra patas, entonces, no deja ir a la gente acudir a sus actividades porque les da miedo.E F. (2012)

Para nosotros es como un desarraigo uno salir de la tierra donde uno nació, de donde lo ombligaron, donde uno creció, pues, donde uno tuvo esa infancia bonita, la conexión con el río, entonces eso significa para uno dejarlo como todo; es como uno volver a iniciar a dar sus primeros pinitos... Usted está por ejemplo en una hábitat y lo trasladan allí, igual usted ya se siente maluco, no se siente cómodo porque usted ya sabe por dónde tenía que cruzar, ya sabe donde iba a buscar su alimento, ya sabe con quién se iba a relacionar, pero ya al trasladarse de allá a acá, eso implicó muchos cambios; cambios en las costumbres, en la cultura, en la vivencia, he cambió totalmente y difícil tener que uno aprender a volver a adaptarse a otro sitio, a otro lugar. E F. (2012)

Esto demuestra quela dinámica del conflicto ha tocado profundamente la vida de los habitantes de Bojayá después de la masacre.
Muchas personas se sienten limitadas en sus labores que les permiten subsistir. El entorno que les produce bienes económicos, tranquilidad social y recursos alimenticios se ha afectado profundamente por las consecuencias del conflicto armado. A partir de la masacre, estos se sienten extraños y in libertades en sus propios territorios para realizar las actividades que les producen bienes económicos.

4. El desplazamiento forzado, producto de la dinámica del conflicto armado, ha causado desarraigo en los habitantes deBojayá al dejar su lugar de origen, aquel que los vio nacer, crecery que les proporciona lo necesario para vivir; también ha causado dependencia del Estadoy de la administración municipal al no poder realizar las actividades que les producen bienestar y por esperar la ayuda extemporánea que el Estado algunas veces entrega.

Aquí recién nos vinimos, habían personas que decían, deberíamos estar en el pueblo viejo, dije ¡Hay pero como se te ocurre que vos vas a ir otra vez allá! No profe, acá estamos mal, estuviéramos allá estaríamos mejor, vea que hay que comprarel plátano y traerlo de allá del puerto;mientras que allá llegamos y ahí mismo estaba ahí el puerto. Las casas están ahí, lo que hacíamos era tirarlo del bote a la casa. Ahora llega la gentede viaje y acá hayque subir el equipaje. Si no hay una bicicleta bregan para traerlo; y si usted viene con algo pesado allá se le queda hasta buscar alguien que lo traiga. Si no llueve las personas tienen que coger un baldado de 
agua, un baldado de ropa de acá para irse para el rio.W.D. (2012)

Ellos mitigan un poco, la necesidad que padecemos los desplazados, porque realmente yo diría que el mejor camino era como crear empresa, donde de pronto se le diera un espacio a cada una de esas personas o por familias, porque $\$ 300.000, \$ 400.000$ pesos para asistirle la casa con cinco seis personas, que el gobierno entrega cada tres meses y después de tres meses ya no lo dan más. Además, algunas veces a personas que lo necesitan no les llega. No les llega porque cuando van a reclamar el subsidio, se ha devuelto nuevamente para Bogotá porque pasaron cinco, seis días y laspersonasbeneficiada se encuentran en un corregimiento, en una vereda y no hay comunicación. MM. (2012)

Como es evidente, el conflicto armado incide directamente en el cambio de vida de las personas, en especial de los campesinos más pobres y luchadores que el conflicto golpea con mayor fuerza y rigor. Según Bello et al. (2005): "El desplazamiento, ya sea dentro de la región o hacia la ciudad capital, altera las prácticas productivas y ocasiona pérdidas concretas de bienes, herramientas, cultivos, animales. A la vez genera pérdidas simbólicas y afectivas que amenazan y deterioran la identidad de las comunidades" (p. 56).

5. La reubicación del pueblo de Bellavista en Bojayá, Chocó, donde se construyeron varias casas, entidades gubernamentales y la escuela, no significa para los bellavisteños una reparación integral. Primero, porque no a todas las víctimas les otorgaron casas. Segundo la reparación integral no se mide solo en términos materiales y económicos que representan la "indemnización". Debe contener la rehabilitación, puesto que muchasvíctimas no han superado las dificultades que les ha dejado la guerra y no tienen las mismas posibilidades en la construcción de su futuro por las afectaciones psicosociales que muchas personas padecen. También la satisfacción, donde se proporcionenbienes y se mitigue el dolor de las víctimas. De igual modo, la no repeticiónnoseha garantizado mediante las políticas del Estado; que no se vuelva a repetir lo vivido.Todavía hay violación de los derechos humanos en esta región y el conflicto armado aún sigue latente, hecho que limita el normal desarrollo de los habitantes. Finalmente está la restitución a las víctimas, a las cuales no se les ha restituido el daño causado. Personas que fueron despojadas de sus tierras y viviendas aún siguen en categorías de desplazados.

A esto se le suma que elpueblo ahora más que nunca está pasando necesidades, dolor, sufrimientos y enfermedades que no han sido reparadas. Un dato más es que las consecuencias del conflicto armado han sido en toda la región del medio Atrato, o que ha dejado muertos y desplazamientos por el despojo de tierras, es decir, la mano visible del Estado no debió ser solo en Bellavista por la masacre de las 119 personas. Esto significa que hay víctimas que aún no han sido contadas, que siguen en la sombra de las cifras oficiales. ¿Dónde está la verdad, la indemnización, la no repetición, rehabilitación y satisfacción de esas víctimas? 
Además, aún siguen presentándose asesinatos que quedan en la impunidad, hostigamientos y personas que aún viven en la diáspora; producto de los desplazamientos forzados.

6. La presencia del Estado en esta zona es escasa, antes y después de la masacre, por lo que los habitantes de Bojayá reclaman mayor presencia; lo culpande su desgracia por el olvido histórico en el que los han mantenido, como lo corrobora el siguiente relato.

Pues la presencia del Estado debería ser múltiple. El Estado debería de estar viniendo o mandando su gente acá diga en el año, tres, cuatro, cinco veces, cada mes; ver cómo está la gente, qué cuenta la gente, qué quiere la gente. Si porque es que en estas cosas generalmente uno mira y dice hombre esto paso, pero el Estado cree que de pronto que con la construcción de este nuevo pueblo, ya arreglamos todo, pero es que una casa no lo es todo. D.C. (2012)

7. La masacre perpetrada en Bellavista, cabecera municipal de Bojayá, tiene tres responsables: el Estado, los paramilitares y la guerrilla de las FARC; los paramilitares por utilizar la población civil como escudo humano y la guerrilla de las FARC por no respetar y distinguir a los civiles de los paramilitares, al atacarlos de manera indiscriminada con un cilindro bomba; así lo expresan algunos sobrevivientes

Yoculpoal gobierno, a la guerrilla y a los paramilitares. ¿Por qué culpo al gobierno? Porque nos abandonó, teníamos una estación de policía y bueno,quitaronlaestación de policía. Y la guerrilla, porque ellosfueron los culpables, ellos enviaron la pipeta a los paramilitares, que ellos también fueron los causantes que laguerrilla enviara la pipeta, porque si ellos no hubieran estado aquícon el pueblo, en el pueblo, yo digoque de pronto no hubiera habido fuego cruzado, la guerrilla no hubiera tenido la necesidad de hacernos daño. R.V. (2012)

8. Hay abiertamente una violacióna los principios constitucionales, derechos humanos, derecho internacional humanitario y demás instrumentos jurídicos del orden nacional e internacional que protegen a la población civil del conflicto armado.El siguiente relato da cuenta de ello:

Habíamos escuchado los disparos y ya todo mundo, bueno, ya sabíamos que en ese entonces se iba a enfrentar la guerrilla con los paramilitares. Pero en ese entonces los paramilitares querían como a los civiles tenerlos de escudo, y querían cubrir pues el pueblo; mientras que la guerrilla, más se acercaban a la población civil, atacaban sin importar que había civiles en el pueblo. E.L. (2012)

Estas narraciones de los actores entrevistados mostraron una zozobra visible producida por los continuos movimientos de las FARC y paramilitares. Los habitantes ya presentían que algo malo estaba por suceder; como efectivamente sucedió. A los paramilitares en su afán por atrincherarse no les importó tomar la población civil como escudo; sabiendo quela mayoría de las personas se encontraban en la iglesia, se apostaron 
alrededor de esta. Este hecho provocó que la guerrilla direccionara todo su accionar militar hacia la iglesia, y atacaroncon cilindros bomba y así destruyeronel lugar.

9)El papel de la diócesis de Quibdó ha sido relevante en esta región, desde su misión pastoral evangélica, la cual ha servido de apoyo a estas comunidades para enfrentar los impactos que impone el conflicto armado, así como de ayuda para mantener viva la memoria de la masacre.

Para nosotros la Iglesia es un sitio sagrado, la gente todavía, digamos, en Colombia tiene un respeto profundo por la Iglesia y, y nos hemos pasado por la hipótesis del ser divino, entonces por eso, la gente buscó la iglesia. Porque era un lugar pues, que para todos era respetable. La iglesia, la casa de Dios, que por años se ha conservado, y dos, por qué corrieron para allá, porque en ese entonces donde nosotros estábamos viviendo en el pueblo viejo, una de las casas de material era la iglesia, entonces vieron ese sitio como un lugar seguro, donde hay una buena estructura, entonces aquí nos podemos proteger; pero cuándo iba a ser uno adivino de que esta gente no fuera a respetar. E.F. (2012)

Así se entiende entones por qué la mayoría de los habitantes deBellavista corrieron a refugiarse en la iglesia para huirde los combates que acaecían, porque la iglesia significa lugar santo y sagrado por ser la casa de Dios, quien los podía proteger de la barbarie; además era una de las pocas estructuras de concreto de Bellavista.
10. El río tiene un valor simbólico y de vida para el hombre y la mujer afrocolombianos que viven en las riveras de los ríos, porque en esteencuentran su sustento, acceso de transporte y porque además permite la satisfacciónde necesidades básicas relacionadas con la higiene: bañarse, lavar ropa y platos. Sin embargo, este se haalejado de la vida de los bellavisteños, por la reubicacióndel pueblo:

Pues, la conexión con el río es como para mí el significado, es como de vida, el río a mí me da vida, porque por medio del río unofluye, uno se baña se siente limpio, hacesus oficios los hace con más espontaneidad, porque allá uno bota su agua, uno coge el agua.No está pendiente de que ¡ah se me va a secar el agua $\mathrm{Y}$ de vida pues, el alimento, porque por ahí es que nos viene el alimento,si no existiera el río pues, uno no consiguiera lo que es el pescadito; y acá la base de la alimentación de todo Bojayá y específicamente de Bellavista es el pescado, entonces es así como vivimos. E.F. (2012)

\section{Hallazgos Relacionados CON LA INSTitución Educativa Departamental César Conto}

1. La IEDCC ha sufrido transformaciones socioculturales relacionadas con la destrucción de su espacio escolar, pérdida de amigos, desplazamiento, transición del proceso educativo y reubicación de la escuela. Esto debido a que la dinámica del conflicto armadoirrumpió abruptamente la tranquilidad con la que la institución contaba por un tiempode más de 
31 años, aspecto que afectóla forma como se construían relaciones dentro de la escuela, como se percibe a continuación:

Gran parte de la estructura física se vino abajo, también, porque la Iglesia estaba pegada con la escuela, entonces se afectó mucho, tanto la parte física como la parte mental; donde nosotros inclusive nos trasladamos hacia Quibdó a partir del 2 de mayo y tratamos conjuntamente en ese entonces entre el gobierno municipal y la rectora con docentes de hacer un trabajo mancomunado y logramos al menos salvar el año lectivo a los estudiantes y retornamos aquí nuevamente para septiembre. Claro que la mayoría de los estudiantes se quedaron en Quibdó, porque inclusive, hasta la fecha de hoy hay estudiantes que no van a regresar jamás, porque todavía viven este dolor de la guerra. G.U (2012)

"Por ejemplo, una de las cosas grandes que me quitaron, fue realmente el espacio donde yo me desenvolvía como niño que lo era todavía. Me quitaron el derecho también a la libertad" M.M. (2012).

Es un hecho grave que la guerrilla atacara la escuela y quelos paramilitares tomaran sus instalaciones para protegerse del enfrentamiento; esto constituye una violación a los derechos humanos y del derecho internacional humanitario; primero porque se destruye la planta física y se impide asíel desarrollo normal al derecho a la educación,y segundo porque es usada como escudo, refugio por paramilitares y blanco de ataquepor la guerrilla. También porque el derecho penal internacional limita a laspartesenconflictoaelegirlibrementelos medios y métodos utilizados en combate, así como disposiciones encaminadas a proteger a las víctimas y a los bienes susceptibles de verse afectados por el conflicto, como las escuelas. No menos importante también es el hecho de que el entorno escolar donde los estudiantes jugaban, compartían y tejían sus relacioneshaya desaparecido.

2. El desplazamiento forzado que tuvo que experimentar la escuela obligó a toda la comunidad educativa a migrar hacia Quibdó, capital del Chocó, donde pasarían muchas dificultades. Lo anterior afectóel proceso educativo yaumentó la deserción escolar. Además de los señalamientos discriminatorios a los que fueron sometidos.

Nos tuvimos que trasladar para la ciudad de Quibdó, donde de pronto no teníamos mucho recurso económico, ya que habíamos perdido todo en Bojayá-Bellavista-, entonces nuestros padres con la agricultura, eran quienes nos ayudaban a salir adelante, nos ayudaban con los uniformes y aquellas cosas que realmente nosotros anhelábamos. A veces inclusive nos decían los "despla, los despla, los despla", porque llegamos totalmente rayados.Yo particularmente llegué con el cuerpo todo cortado, por muchas espinas,fueron 2 días dentro de la selva corriendo, donde habían muchas espinas, y pues yo como no tenía muletas porque tenía una sola pierna, me tocó muy duro, porque me tocaba arrastrarme. M.M. (2012)

Esto se comprende como una afectación directa en el proceso de enseñanza-aprendizaje de la Institución César Conto, debido 
a que el desplazamiento hacia Quibdó fue difícil, ya que contaron con varios inconvenientes: educativo, social y económico. Los de tipo educativo se vieron reflejados en la medida en que no se pudo garantizar la continuidad y permanencia de todos los educandos en Quibdó, debido al cambio de contexto y por lo que implicaba estar en condición de desplazamiento; sin casa, sin dinero y sin alimentación para sobrevivir, así como la falta de apoyo de familiares, quienes podían brindar ayuda.

3. La IEDCC salió afectada porque se encontraba relativamente cerca a la iglesia, donde estaban los civiles alojados para protegerse, y fue alcanzada por los proyectiles y las hondas explosivas del cilindro bomba.

La escuela quedaba a mano izquierda entrando hacia la iglesia, que a mano izquierda quedaban las dos pegadas; entonces, todos esos explosivos y todos esos artefactos pesados pegaban también a la escuela, porque la iglesia se cayó y entonces quedó desprotegida, entonces todas esas balas tendían a pegar en la escuela, porque ellos también se refugiaban allá, los paramilitares, entonces cuando la guerrilla lanzaba balas, granadas y todas esas cosas, que se estrellaban allá. Muchos estudiantes no alcanzaron a graduarse en su lugar de nacimiento, que era la escuela mixta de Bella Vista, entonces, por eso la escuela quedó afectada también, porque se quedó sola sin estudiantes y sin profesores, ya todo mundo buscó para donde irse. M.M. (2012).

4. Los hechos y horrores vividosproducto de la barbarie del conflicto armado han generado afectaciones psicosociales en algunos actores educativos, lo que ha ocasionado deserción estudiantil, dado que algunos sujetos no quieren volver al entorno educativo por el impacto que generó la masacre en sus vidas."Pues oiga, le digo que para nosotros por ejemplo ha sido un marcante, que eso lo lleva uno de por vida, la masacre; masacrar digamos a 119 personas es una cosa, digamos, que fue bastante dolorosa, muy fuerte" G.U. (2012). "Hay hechos muy crueles como el de una mujer que estaba en embarazo dentro de la Iglesia y cuando estalló la pipeta, las ondas explosivas le abrieron el vientre se le rajó y el feto lo hallaron en un salón de la escuela" M.M. (2012).

5. La IEDCC al entrar a la categoría de desplazada y reubicada entró en un comienzo a un periodo de transición por cinco años, lo que hacíaque el proceso educativo fuera intermitente, puesto que la escuela tuvo que paralizar sus actividades en la huida de Bojayá hacia Quibdó, de Quibdó retornó a Bellavista Viejo y en 2007 se reubicódefinitivamente en Bellavista Nuevo, como lo permite comprender a continuación este entrevistado.

Sobre la reubicación de la escuela,hubo que esperar bastante tiempo, porque fue por etapas, donde la gente del pueblo quería reubicarse en el mismo pueblo viejo. Hubo una reunión de los barrios y de todas las juntas de acciones comunales y llegaron al acuerdo que se iban a trasladar para el cerro, para Ceberá, un lugar donde es bastante montañoso, al lado del cementerio, entonces ya empezaron a demoler eso, pero 
legalmente fue una pelea dura con el Estado, porque el Estado promete pero no cumple. M. M. (2012)

7. A raíz de las escenas de horror vistas, el ambiente de tensión del conflicto armado ha generado a través de todos estos años comportamientos desencadenados en agresividad por parte de los estudiantes; así lo representan las siguientes voces:

Entonces esos son todos los impactos que han creado de tanta violencia acá. Los niños se pelean, esas, esas riñas, esas riñas se han intensificado, con todo lo de la violencia, eso es un impacto muy grande porque se pelean los niños. Acá ya hasta los mismos mayores se mantienen...,el uno vive tirándose con el uno, ya. La gente como que, estamos como aprendiendo a vivir como por grupitos, con el mío apenas y ya, No le interesa lo de la comunidad. Está duro para vivir esto acá, uno se sorprende. E.F. (2012)

Ya en mi óptica, digamos sicológica, le digo, digamos, que los pelados se han vuelto bastante violentos, muy violentos, producto, digamos, de la violencia que se vive aquí, y si mira por ejemplo nosotros en el año 90, 80, la gente de aquí poco venían aquí, pero ahora por ser cabecera municipal vienen muchagente de las comunidades; el caso de Carrillo, el caso de la Loma, el caso de Veracruz y en la cual eso ha influido mucho a que, a que se mezcle la parte comportamental y la verdad es que los pelados son bastantes tremendos muy tremendos. G.U. (2012)

Al respecto, la Fundación Dos Mundos (2009), comprende muy bien la agresividad que puede desencadenar una víctima del conflicto al aseverar que "el rango de expresión emocional puede aun ser mayor e incluir desde aislamiento, frustración y miedo, hasta crisis de pánico, llanto frecuente, retraimiento, aislamiento, dificultad para concentrarse e ideación suicida en algunos casos" (p. 75). Todo lo anterior hace que su convivencia, que es de vital importancia para asegurar la vida armónica y el orden pacífico, sea seriamente afectada, como se infiere, a partir de las narrativas analizadas.

8. La masacre colectiva ocurrida en Bellavista ha generado orfandad en la escuela, dado que hayniños y niñas huérfanos que han tenido que ser adoptados por vecinos o personas extrañas al contexto, o muchas veces han sido relegados a un tutor que los pueda cuidar.

Unos compañeros que se quedaron sin papá y sin mamá, afortunadamente y les tocó que los adoptaran, o, les tocó que algunos padreslos dieran en, o sea, dárselo a alguien que la supiera cuidar bien y que, aja, velara por ella porque acá prácticamente desde que pasó eso casi no se ve ,digamos, la economía". V.M. (2012)

9. Se presenta carencia de políticas internas en la IEDCC para hacer memoria de sus sucesos vividos en medio del conflicto armado, pues no hay políticas que permeen el proyecto educativo institucional (PEI).Aún así, se resaltan las iniciativas de algunos docentes que desde sus prácticas pedagógicas hacen ejercicio de memoria. Es decir, esta institución no ha visibilizado el ejercicio de la memoria en su contexto escolar como un dispositivo que puede incidir 
en los procesos de enseñanza-aprendizaje, por ello solo hay de manera muy particularizada dentro del campo disciplinar iniciativas que posibilitan que los estudiantes evoquen recuerdos, en algunos ensayos escritos que los docentespresentan, perono de manera articulada.

10. La IEDCC ha asumido un papel pasivo en las conmemoraciones anualesque se hacen sobre la masacre, dado que limitan su accionar en solo acompañar y ayudar a la diócesis de Quibdó. Es decir, no apropia los escenarios internos para realizar prácticas de memoria sobre la masacre.

Cada 2 de Mayo, que se hace la celebración; entre docentes, siempre participamos, por decir algo, de la eucaristía. Yo, trabajé mucho tiempo con la Iglesia y me he quedado allí. ¿Cómo le digo? Siempre mi trabajo con la Iglesia, los docentes recordamos el 2 de Mayo y preparamos todo. Hacemos los arreglos florales, hacemos los cantos y logramos que la misa sea especial, una eucaristía concelebrada, con danzas, con cantos, etc., y se integran con las otras gentes de otros pueblos, ylos profesores están metidos también; de manera que; tanto docentes como estudiantes recordamos de esa manera los hechos vividos para esa época. W.D. (2012).

11. La IEDCC no ha reestructurado el currículo que le permita afrontar las situaciones que ha experimentado por causas del conflicto armado. Por eso se sobre entiende la poca articulación de prácticas sobre memoria.
Esta inferencia tiene su asidero en la siguientenarrativa:

No, cambiosno se hicieron en el currículo, sino que a través de la cátedra de afrocolombianidad, se le han hecho algunas variaciones. Se han tocado algunos temas por ahí, pero cambios significativos no. Inclusive yo ahora que me dan la oportunidad, hablo con mucha propiedad porque yo fui estudiante aquí, yo fui fundador. G.U. (2013)

12. La masacre para la la IEDCC tiene un sentido y significadode crueldad, porla forma como perdieron la vida estudiantes y padres de familia en aquel evento, así comolas cicatrices que aún llevan de por vida. También porque no entienden cómo de un momento a otro llegó el conflicto armadoa sus vidas dy destruyó muchas cosas, incluyendo su escuela.

Yo no le veo como sentido, es un acto que por donde se mire es ilógico, un acto irracional y el significado, pues lógico la pérdida de muchos estudiantes, esto nos lleva a una gran reflexión y como yo le decía que esta confrontación armada en Colombia va mucho más allá .Ya cruzó la barrera del acto de barbarie.La verdad que esto ya es irracional, en donde no se respeta a la vida de niños ni de estudiantes. Hay un desprecio por la vida humana. J.M. (2012).

Como se alcanza a percibir, el sentido y significado por las pérdidas humanas, destrucción de la escuela y las cicatricescausadas por los actores armados en medio del conflicto son consideradas comoactos perversos 
y hasta irracionales, porque tales hechos no tienen excusa justificable, así quienes hacen la guerra pretendan buscar pretextos para validar y justificar estos hechos en medio del conflicto armado ante la población civil.

\section{Conclusiones}

A partir del análisis de los resultados fue posible recuperar la memoria de la IEDCC develando en las voces de los actores escolares que no hay un sentidosobre la masacre, ni nada que justifique aquella trágica matanza, las afectaciones materiales, económicas, sociales, culturales, morales, físicas, religiosas y psicológicas de los sobrevivientes; solo les quedan algunos intentos por situar lo que fueron los hechos en el antes, durante y después, aceptando que la vida debe seguir, así sea en medio del dolor y el sufrimiento.

El desarrollo del conflicto armado que generó la masacre, el desplazamiento, la destrucción del espacio físico y simbólico, transiciones del proceso de educabilidad, los traumas psicosociales, agresividad, el desarraigo, deserción escolar, reubicación y marginación entreotras realidades nefastas que les tocó vivir a la IEDCC causaron efectos devastadores en su dinámica escolar, en lo relacionado con el proceso educativo y las transformaciones socioculturales quehan afectado la subsistencia, relacionando sus prácticas productivas y sociales dentro de la institución, Bojayá y sus alrededores. Las afectaciones del proceso educativo se resumen en: 1) las pérdidas de vidas humanas, dado que muchos estudiantes, docentes y padres de familia perdieron la vida; 2) la destrucción de la escuela significó el derrumbe de sueños, anhelos, afectaciones psicosociales, agresividad, orfandad y una pérdida de paz y tranquilidad que había durado por un espacio de 31 años. Este acontecimiento destruyó y se afectó la infraestructura de la institución educativa, y derrumbó así el sueñode estudiantes, padres de familia y maestros, y 3) la transición del proceso educativo también ha significado para estas personas la destrucción de su mundo simbólico, una pésimareubicación dela escuela, dolor por sus familiaresy amigos muertos.

Respecto a la primera afectación, el espacio escolar marcaba las interrelaciones de los sujetos dentro de la escuela, compartiendo emociones, tristezas, jugando, estudiando y gozando de su libertad y sana comunicación y convivencia; y este ha desaparecido. En cuanto a la reubicación dela escuela,estase ha entendido como un atraso al proceso educativopor la demora en su construcción, porque experimentan un triple desplazamiento. El primero se da con la huida hacia Quibdó, donde viven muchas dificultades; el segundo es el retorno a su lugar de origen debido a la mala atención gubernamental brindada en su momento en Quibdó, lugar quelos obligó a regresar a Bellavista,y el tercerodesplazaientose da desde Bellavista Viejo al Bellavista Nuevo, donde se inaugura la construcción de la nueva IEDCC.

En lo concerniente a la segunda, el dolor por sus familiares y amigos muertos con quienes tejíansu mundo simbólico escolar se mantiene vivo en la memoria al recordar el ser querido asesinado o desaparecido y no puede alejarse porque alimenta la memoría. También han aprendido a vivir sin ellos, elaborando un duelo colectivo, viviendo en situaciones de tensión emocional por sus pérdidas. Ahora, si bien es cierto que en 
cuanto a los traumas psicosociales se refiere no hay diagnóstico real frente a la situación mental de los actores entrevistados, es necesario mencionar que en sus discursos hay características que pueden dar indicios para pensar en la configuración de trastornos como de estado de ánimo, cada vez que se presenta una alteración del humor, es decir, que al recordar lo sucedido seproduce rabia o tristeza, trastornos de ansiedad, toda vez que en sus narrativas se evidencia angustia, miedo, terror, aprehensión por el accionar de actores armados. Respeto a la agresividad, se infiere que por las consecuencias psicológicas de la violencia de la guerra, estos sobrevivientes han sido personas expuestasy han sido obligados a desconfiar $\mathrm{y}$ vivir en medio de la zozobra y el miedo. Las huellas en su humanidad, ansiedad generalizada,pérdida de la ilusión, desánimo, disminución del gozo, añoranza, sensación de vacío, desilusión, sentimientos de desprotección e indefensión los ha vuelto más sensibles y con ellos los niveles de agresividad aumentan en la escuela.

Finalmente, sobre la orfandad, se puede decirque hay unas víctimas silenciosas: los niños huérfanos que han perdido a uno o a sus dos padres; de esta manera entran a un cambio de vida completamente distinto. La situación de muchos niños en Bojayá es muy triste; después de la masacre fueron delegados y adoptados por diferentes personas o familias, muchas veces ajenas a su cultura, porque sus padres fueron masacrados, y otros se enfrentaron a la diáspora del destierro, sobreviviendo a su suerte al no querer regresar más a dicho lugar, hasta el punto que actualmente no se tienen noticias de algunos de ellos.
La tercera, referente a las transformaciones socioculturales, ha afectado la subsistencia de los habitantes relacionando sus prácticas productivas y sociales dentro de la institución, Bojayá y sus alrededores debido a los desplazamientos, reubicación del pueblo, poca presencia del Estado colombiano en la zona y una reparación demorada. A propósito de reparación, si bien es cierto que existen varias capturas y sentencias del Tribunal Contencioso Administrativo del Chocó, esas no ha sido realizadas a plenitud por el Estado.

Por otra parte, cabe resaltar que antes de la masacre, se presentaron violaciones, desapariciones forzadas, reclutamientos, torturas, cayeron civiles en minas antipersonal homicidios selectivos y desplazamientos en Bojayá y sus alrededores. Lo mencionado anteriormente se presentó como una estrategia para amedrentar, sembrando el miedo y el pánico con el objetivo de apoderarse de muchas tierras de la región del medio Atrato por parte de empresarios, latifundistas, transnacionales, actores armados, con el apoyo de agentes del Estado colombiano. En consecuencia, esto afectó profundamente la vida de los habitantes de Bojayá después de la masacre, e hizo que las personas se sintieran limitadasen cuanto a realizar sus labores y actividades que les producen bienes económicos, tranquilidad social y recursos alimenticios, como la siembra de pancoger y la pesca.

Los desplazamientos se dieron por varios intereses económicos y de estrategia militar, por las bondades económicas y estratégicas que representa esta región del medio Atrato. Los desplazamientos no son un hecho fortuito, aislado de los intereses que aquí 
se develan. Los intereses económicos se enmarcan en la siembra de monocultivos, palma de aceite ymega proyectos en la construcción de energía, extracción de recursos minerales e interconexión portuaria; pues esaquí en Bojayá donde se construirían dos posibles canales interoceánicos Atrato-Napipi en Bojayá y Atrato Truandó en el municipio de Rio Sucio, que limita con Bojayá.

En cuanto a la reubicación del pueblo de Bojayá, la cual ha sido exaltada como algo sin precedente en la historia reciente de Colombia por los gobiernos de turno, como una respuesta integral de reparación a las víctimas y de atención de sus necesidades, ha traído consigo consecuencias y transformaciones en la forma de vida de sus habitantes y su relación con el río, ya que este se encuentra alejado; hecho que hace más difícil la pesca y la realización de actividades básicas de higiene como acueductos, lavaderos, balnearios y alcantarillados.

En relación con la presencia del Estado, este no ha centrado su atención en todas las personas víctimas del conflicto armado desarrollado en esta zona y tampoco ha creado políticas y estrategias serias para garantizar la paz, tranquilidad y estilo de vida digna de estas personas. El Estado colombiano no está cumpliendo con su obligación constitucional y tampoco ha ejercido un compromiso de fondo con esta comunidad, debido a que la ayuda que les llega no alcanza a satisfacer a estos habitantes del municipio, como tampoco a pueblos vecinos.

Finalmente, se concluye que el papel relevante en la construcción de la memoria en las instituciones educativas que han sido afectadas por la guerra debe asumirse desde la escuela como una apuesta que requiere la participación de sus actores educativos, para resignificar y comprender los fenómenos de la violencia, los cuales permean la escuela. Esto se debe asumir desde la gestión educativa y pedagógica con mecanismos, estrategias y políticas que permeen el PEI, que ayuden desde los procesos de formación y educativos, al entendimiento ya la prevención del conflicto armado, para así hilar memorias colectivas y crear conciencia, evitar la impunidad y el olvido. También porque seria novedoso ver cómo la escuela puede aprovechar su tragedia, con la ayuda de la memoria para crear conciencia, aspecto que afectaría de manera positiva su proceso de educabilidad.

\section{REFERENCIA}

Bello, M., Cardenal, E., Millán Echeverría, C., Pullido, B. et al. (2005). Bojayá, memoria y río. Violencia política, daño y reparación. Bogotá: Universidad Nacional de Colombia.

Caracol Noticias (septiembre, 2005). Presidente y cúpula militar de la época, a responder de su bolsillo por Bojayá. Caracol Noticias. Recuperado de:http:// www.noticiascaracol.com/colombia/ presidente-y-cupula-militar-de-la-epoca-responder-de-su-bolsillo-por-bojaya

Centro de Investigación y Educación Popular (2002). Caso tipo 1: Bojayá, la otra versión. Bogota: Centro de Investigación y Educación Popular [Cinep].

Comisión Nacional de Reparación y Reconciliación (2010).Bojayá: la guerra sin límites. Recuperadodehttp://www.centrodememoriahistorica.gov.co/index.php/ informes-gmh/informes-2010/bojaya

Comisión Nacional de Memoria Histórica (CNRR) (2013) ¡Basta ya! Colombia: 
Memoria de Guerra y Dignidad. Bogotá: Imprenta Nacional.

Defensoría del Pueblo. (25 de mayo de 2002). Informe defensoría humanitario 1 . Recuperado de www.acnur.org/t3/uploads/pics/ 2464.pdf? view $=1$

Fundación Dos Mundos. (2009). Escuela y conflicto armado: de bien protegido a espacio protector. Aportes psicosociales para enfrentarlas violaciones de los DH y DIH. Bogotá: autor.
Merlino, A. (2009). Investigación cualitativa en ciencias sociales. Temas, problemas y aplicación. Buenos Aires: CengajeLearning. Verdad Abierta. (2009). Noel Palacios, músico sobreviviente de Bojayá.Verdad Abierta.Com. Recuperado dehttp:// www.ver dadabierta.com/victimas-seccion/perfiles/1896-noel-palacios-musico-sobreviviente-de-bojaya- 